\title{
Un mapa de los estudios latinoamericanos y españoles sobre videojuegos
}

\section{A map of Latin American and Spanish studies on video games}

\author{
Luis Sebastián Ramón Rossi* \\ *Faculty of Educational Sciences - National University of Entre Ríos (FCEdu UNER)/National Scientific and Technical \\ Research Council (CONICET), Argentina
}

\section{Resumen}

\begin{abstract}
En este artículo exploraremos las principales tendencias analíticas de la investigación sobre videojuegos en América Latina y España. Para ello presentaremos tres vías de análisis de los videojuegos cuya presencia es indudable en nuestro contexto regional e idiomático. Primero nos abocaremos a los intentos de definición de los juegos digitales desde aquellos estudios que hacen hincapié en su carácter narrativo hasta los que subrayan sus componentes interactivos. En un segundo momento, rotaremos el eje de análisis para comprender la centralidad en el contexto elegido de las aproximaciones sobre videojuegos que indagan su relación con la educación y el aprendizaje. Por último, nos concentraremos en las investigaciones que ven a los videojuegos como problemas para las teorías sociales. En el último apartado señalaremos cuánto pueden ayudar estos múltiples aportes de diversas tradiciones teóricas para pensar nuevos problemas (como los que se desprenden de las actuales condiciones de producción de videojuegos en la región delimitada).
\end{abstract}

Palabras claves: videojuegos y educación; definiciones de los videojuegos; videojuegos y sociedad; estudios latinoamericanos y españoles de juegos digitales.

Abstract

\begin{abstract}
This paper approaches the main analytical trends in video game research in Latin America and Spain. To achieve such aim, three paths are followed analyzing video games, which are undoubtedly present in our regional and idiomatic context. Firstly, the attempts to define digital games -starting from those studies highlighting their narrative nature to those which underscore their interactive components- are addressed. Secondly, attention is turned to understanding the core issue of the approaches linking video games with education and learning in the chosen context. Finally, this study focuses on research which regards video games as problems in the field of social theories. The last section points out how much these multiple inputs from diverse theoretical traditions may contribute to the creation of new problems, as those arising from the current conditions of video game production in the region chosen.
\end{abstract}

Keywords: video games and education; definitions of video games; video games and society; latin american and spanish digital games studies.

\section{Introducción}

La intención fundamental del presente artículo es realizar un breve recorrido por las vías y alternativas analíticas más comúnmente transitadas de la investigación sobre videojuegos en América Latina y España ${ }^{1}$. La elección del recorte bibliográfico que conforma este estudio no es azarosa sino que responde

\footnotetext{
${ }^{1}$ Evidentemente un recorte regional e idiomático de tal naturaleza no nos impedirá citar fuentes de otros orígenes, como es el caso de la literatura anglosajona que forja vías analíticas muy influyentes sobre el campo. Ahora bien, ha de tenerse en cuenta que futuros trabajos deberán sistematizar las corrientes de pensamiento sobre videojuegos en otros contextos, por ello nos hemos limitado a señalar sólo influencias sensibles. Al mismo tiempo dada la extensión
} 
a la necesidad de trazar los rasgos de un campo interdisciplinario en crecimiento constante, pero excesivamente disperso e informal. Esta dispersión de los análisis está estrechamente ligada a la histórica condición de los países de la región como consumidores de videojuegos antes que como productores, pero también obedece a cierto carácter novedoso del tema. Sin embargo, la percepción de la novedad es engañosa y más aún lo es su aparente lugar académico marginal como lo han demostrado recientes tipologías teóricas de estudios sobre videojuegos (Navarrete et al., 2014; Planells, 2013).

Frente a este panorama de relativo desconocimiento, el objetivo principal de nuestro escrito es el de aproximar al lector a la riqueza temática de múltiples autores e investigadores que han contribuido a problematizar a los videojuegos (en alguna correspondencia con investigaciones que han intentado empresas similares para el juego en general como la de David y Blasco (2006)). Así, la metodología que vertebra este trabajo fue la de un análisis cualitativo de corte hermenéutico-crítico de los textos que componen la literatura existente sobre videojuegos en España y América Latina. El conjunto de textos que conforman la bibliografía sobre videojuegos en el contexto seleccionado permite comprender la amplia dispersión sobre el tópico trabajado, así como el abordaje desde distintas perspectivas discursivas. Esta diversidad a su vez posibilita una lectura textual e inter-textual de la interrelación entre problemas, disciplinas y concepciones teóricas que han intentado perfilar, definir y diagramar explicaciones e interpretaciones sobre los videojuegos desde tradiciones heterogéneas.

Así, si bien en América Latina y España existen antecedentes de investigaciones psicológicas desde mediados de la década de 1980, será a partir del decenio siguiente que se producirá un notorio crecimiento de la literatura especializada en el contexto regional e idiomático elegido (hasta llegar a cierta multiplicación casi inabarcable en la actualidad). Curiosamente, gran parte de los estudios revisados a continuación, cumplen con las indicaciones que Egenfeldt y Tosca (2008) formularon acerca de las producciones angloparlantes. Durante la década de 1990 la literatura parece responder a las consideraciones teóricas generales sobre los Nuevos Medios digitales, donde los videojuegos adquirirán un rol particular como ejemplificaciones de formas narrativas novedosas, de interfaces interactivas, de búsquedas artísticas, etc. A medida que avanza el nuevo milenio, la teoría parecería cerrarse sobre el videojuego como objeto único y particular que requeriría análisis específicos (Game Studies). Con este giro, conocido a menudo más allá del contexto elegido como el debate entre ludólogos y narratólogos ${ }^{2}$, se

bibliográfica del trabajo y la mayor publicidad de autores angloparlantes hemos optado por indicar al lector que confronte nuestros dichos con la obra de los mismos.

2 Desde mediados de la década de 1980 la investigación académica en Ciencias Sociales y Humanidades, tanto en Europa como en los Estados Unidos, comenzó a dedicarse a los videojuegos. Los primeros trabajos, amén de las pioneras indagaciones de desarrolladores de principios del decenio citado (como C. Crawford), vendrían de perfiles académicos mixtos que encontraban raíces comunes en los estudios literarios y en los New Media Studies. Estos resaltaban la centralidad de las ficciones, tramas e historias (cfr. Jenkins y Fuller; Turkle y Murray). No obstante, hacia principios del siglo XXI, surgieron controversias acerca de la validez de estos enfoques narratológicos que descuidaban lo que se conocería como mecánica lúdica en la descripción tanto de los procesos de juego como de invención de videojuegos (cfr. Mäyrä, Egenfeldt, Smith y Tosca, 2008; Salen y Zimmerman, entre otros.). Así nacieron algunas perspectivas autodenominadas ludológicas por su búsqueda de fundar ciencia o logos del juego, ludus (muchas de ellas refiriendo a clásicos como Huizinga, Caillois o Sutton Smith). Estos estudios definirían al juego como sistema de reglas, con resultados variables y estructuras o configuraciones de la actividad del jugador, al tiempo que muchos de ellos, reaccionando contra el lugar privilegiado de los análisis de la representación, se dedicarían a la indagación minuciosa de las interacciones con el mundo audiovisual-táctil y la simulación (algunos ejemplos se encuentran en J. Juul, G. Frasca, Kampmann, Eskelinen, Galloway, Djaouti, Aaserth, Järvinen, Carr, entre otros). Una de las tesituras básicas de este grupo es que las historias de los juegos son ornamentos; un envoltorio de regalos, con consecuencias limitadas en las experiencias de juego o gameplay. No obstante, en primer lugar, los ludólogos reconocen cierto valor a la tematización, a la retórica y a la narración como vía de presentar al jugador una comprensión intuitiva y metafórica del sistema de reglas que constituye el juego. En segundo lugar, su formalismo (heredado de Parlett) no les impide que se enfoquen 
señala, desde 2001, una suerte de recuperación de corrientes teóricas ligadas al formalismo, al estudio de las reglas y al análisis de los videojuegos ya no como piezas literarias sino propiamente como juegos.

No obstante, en el contexto de nuestra investigación el tipo de disputas anteriormente referidas apenas tuvo injerencia, aún si algunos rastros son legibles en los primeros estudios que abordaremos dirigidos a especificar las características centrales de los videojuegos. Con todo, como veremos enseguida, en América Latina y España, la mayoría de las investigaciones vendrían de tradiciones académicas como las Ciencias Sociales y las Humanidades, de allí que en la segunda y tercera sección del segundo acápite nos aboquemos a dichas perspectivas. En primer lugar, nos detendremos en la gran proliferación de estudios provenientes de las Ciencias de la Educación que abordan dimensiones psicológicas, ontológicas y sociológicas de los videojuegos. En segundo lugar, abordaremos exploraciones sobre los videojuegos que los han puesto en contacto con dimensiones históricas, políticas, culturales y sociales. A la fecha no tenemos registro de revisiones bibliográficas que hayan intentado poner en diálogo y comprender estas alternativas analíticas heterogéneas. Por ello también nos hemos abocado a conformar este recorrido, con la esperanza de que futuras indagaciones abran espacios de diálogo entre disciplinas que, construyendo objetos muy cercanos, parecen no interpretarse mutuamente.

Por otra parte, nuestra intención de realizar un mapa de las tendencias analíticas más recurrentes no significa que podamos desglosar aquí en detalle cada una de ellas o que cada autor pueda tener el tratamiento extenso que seguramente merece. La tarea reconstructiva apunta, en principio, a recuperar los elementos principales que complejizan las actuales tendencias investigativas para llegar a postular algunos espacios vacantes en los que se podrín inscribir otros estudios. Allí apuntará el último acápite en el que destacaremos las posibilidades heurísticas positivas que podría tener la problematización del videojuego desde nociones que lo pongan en contacto con las tendencias del capitalismo contemporáneo.

\title{
Tendencias de análisis de videojuegos en América Latina y España
}

\author{
Ejes de definición de los videojuegos: de la narración a la interacción
}

A las investigaciones pioneras que surgieron durante el siglo pasado ${ }^{3}$, en el contexto idiomático y regional que hemos señalado, le siguieron aproximaciones semióticas, psicoanalíticas, antropológicas y

en problemas políticos y retóricos (como es el caso de la tesis doctoral del uruguayo G. Frasca), o en la combinación de
reglas y ficción (como Juul). No obstante, debe quedar claro que el argumento de los ludólogos es ontológico: los
juegos no son narrativas o historias. Esto no ha de confundirse con la idea de que los juegos no puedan contener
narrativas, historias o algún grado de narración, sino que cualquier otra cosa diferente a las mecánicas y dinámicas del
juego es extraña a su forma onto-estética (Eskelinen, 2012). Aunque muchos de los supuestos de los narratólogos los
veremos como parte de las investigaciones latinoamericanas y españolas, ya que influyeron netamente en ellas,
digamos que las teorías sobre narrativas en el estudio de los juegos, por lo general, provienen de campos como los
estudios literarios. El núcleo de sus ideas se resume diciendo que el juego es un mundo de historias audiovisuales en
las que el jugador asume los roles de co-narrador y protagonista, así como la gameplay se vuelve un tipo espećíico y
complejo de narración. Para Thabet (2015), una de las más recientes contribuciones a esta línea, está noción de
mundos en los juegos es paralela a la noción de "textos" en la literatura de ficción. De allí que sus preguntas se
formulen en torno a cómo se cuenta esa historia y cómo se la interpreta, pues el juego es un arte performativa y
dramática (como sostienen Murray y Ryan). Por último, hay que señalar que en las postrimerías de estos debates
surgirá la necesidad de pensar a los videojuegos de manera interdisciplinar, acercando ambas posiciones.
3 Hacia 1997 el investigador argentino D. Levis, destacaba que los videojuegos en sus múltiples plataformas
constituirían un primer acercamiento a la informática a través de las pantallas de televisor como tecnología masiva de
interactividad. Esta masividad permitió abrir un camino en el cual la exploración del campo iba de la mano de la historia 
comunicológicas. La mayoría de estas pesquisas han abordado la construcción de sentido con videojuegos enfocándose en una suerte de carácter narrativo de los mismos.

A diferencia de las demás tendencias, este carácter narrativo de los videojuegos parece ser un eje dinámico y transversal que atraviesa diferentes disciplinas, campos e intenciones de análisis, pues al tiempo que permite definir (ontológicamente) al juego, favorece la construcción de marcos analíticos y metodológicos. Sin embargo, en una gran mayoría de los autores que dominan en la región pueden notarse vías interpretativas que exceden el carácter narrativo explorando la interacción definida por la interfaz, así como la taxonomía de contenidos y, en algún punto, cierta consideración de problemas relacionados con las mecánicas y dinámicas de los juegos.

Así, una de las tendencias de investigación más difundidas y desarrolladas ha sido la que examina a los videojuegos desde el punto de vista de su potencial narrativo. Una versión estándar de estos autores diría que los videojuegos son equiparables a textos con un sistema de significación y funciones narrativas claras que permitirían generar en los jugadores experiencias emocionales mediante la inmersión en una trama y la reconstrucción de una o varias historias (Esnaola, 2006). Dicha cualidad se ve vehiculizada esencialmente por el lugar del jugador como protagonista vicario del relato quien dramatizaría la narración en el marco de diferentes opciones de continuidad ligadas al progreso por las instancias del juego ${ }^{4}$ (Scolari et al. 2013; Peinado y Santorum, 2004, 2006). Estas instancias representan una serie de eventos cuya totalidad arma un relato pasible de ser narrado o de emerger en cutscenes, materiales audiovisuales introductorios, campañas de marketing, foros, revistas especializadas, embalajes comerciales, etc. Estas producciones generan todo un corpus que puede ser analizado con los instrumentos que el análisis del discurso (a veces multimodal) permite manejar. Por la marcada discontinuidad que afecta al campo es difícil encontrar secuencias claras de escuelas, maestros y discípulos, no obstante hay trabajos como los de Scolari et al. (2013) que se vuelven centrales pues coronan varias décadas de investigación en diversas direcciones y se han vuelto guías fundamentales para quienes se inician en estos análisis.

Una de las dificultades para señalar continuidades y rupturas entre líneas de investigación en este eje, está estrictamente ligada a que las referencias conceptuales a menudo están tomadas de la literatura angloparlante. Puesto que estas interpretaciones del juego como relato o soporte de los mismos, tienen sus raíces en la recepción, hacia finales del siglo pasado, de estudios norteamericanos cuyos referentes básicos se encuentran en los New Media Studies y en aproximaciones narratológicas como las de J. Murray, H. Jenkins, y M-L. Ryan. Todos ellos parten, a veces sin definiciones claras y con usos indiscriminados de la noción de narrativa (Eskelinen, 2012; Juul, 2005), de que los videojuegos son híbridos entre juegos y narraciones (espaciales, fantásticas, épicas, etc.) y, por lo tanto, se centran en las cualidades representacionales de los mismos (con frecuencia para describirlos de acuerdo a modelos literarios y dramáticos).

Así, los videojuegos se asemejarían a narraciones o relatos ficcionales en la articulación de diferentes secuencias de acciones, estados y situaciones (problemas, desarrollos y resoluciones) que se suceden en

de la industria, del análisis de los discursos generados en revistas no científicas así como en la presentación de taxonomías de los géneros. Un poco antes, los estudios de psicología de la personalidad del investigador español Estallo (1994, 1997), serán señalados como uno de los primeros en lengua castellana en intentar unir diversos tipos de videojuegos a modalidades perceptivas y en preguntarse, al mismo tiempo, por su relación con la autoestima y su influencia sobre el carácter y la estructura de la personalidad.

4 No es casual que entre los géneros comerciales más analizados por estos estudios se encuentren las aventuras gráficas. 
una temporalidad delimitada. Ello supondría además un trabajo equiparable del jugador como lector, quien comprendería hermenéuticamente el encadenamiento de las secuencias, en un universo narrativo de un juego que puede ser visto como lenguaje, medio de expresión o formación discursiva (entidad generadora de sentido) (Lemos, 2013; Pérez, M., 2010).

A esta analogía le corresponde la traducción de modelos analíticos propios del cine y la literatura a los videojuegos y viceversa (Ponce y García, 2012). En primer lugar, estos marcos parten de la separación de la vida cotidiana propiciada por un conjunto de reglas generadoras de ficción narrativa, así como del análisis de personajes, conflictos, tramas, etc. En segundo lugar, la comparación permite hipótesis de orden psicológico sostenidas en la reaparición de las modalidades narrativas de constitución del self (Bruner, passim.), pues el videojuego se convierte en un artefacto ficcional que, al privilegiar las acciones como motor de su dinámica, lleva aparejados contenidos emocionales y cognitivos narrables (Balaguer, 2007). Esos contenidos se anclan en la capacidad que los jugadores tienen de contar relatos sobre una sesión lúdica (de allí que algunos estudios elijan esa vía para llevar a cabo sus análisis) (Esnaola, 2006). Ahora bien, las similitudes frecuentemente señaladas entre videojuegos y otros soportes narrativos no han ido en detrimento del descubrimiento de múltiples diferencias ${ }^{5}$. De acuerdo a estos estudios, en la narrativa (al menos en su formato tradicional) las historias están cerradas, tienen una estructura estable y se organizan por un narrador (o un director) que señala la pauta de acceso a los eventos. En los videojuegos, por el contrario, el destinatario deja de ser mero receptor para convertirse en protagonista y la historia evoluciona si efectivamente se da esa participación; esto supone la elección de diferentes posibilidades de continuación de la narración y la inauguración de diversas temporalidades ${ }^{6}$ (Scolari et al., 2013). Con ello se pondría en crisis la narración cronológica y toda trama secuencial (ordenada de principio a fin) que suponga una estructura con un solo tipo de lectura. Para diversos autores estas modificaciones hacen precisas para el jugador una estética y una pragmática diferente a la del espectadorlector (Torres et al. 2015).

A este contraste en el estilo narrativo se le suma, habitualmente, el lugar del narrador, en el carácter de narración-performance del videojuego (por contraposición al relato estándar como enunciación narrativa) (Núñez, J., 2007). El jugador aparece como actor que re-actúa un drama (desprendido quizás de la familiaridad de la noción de play con el universo teatral). De allí que a menudo se señale como diferencia con los soportes narrativos más habituales, el concepto de final variable o indeterminación potencial propia de todo juego. Esto es, frente a los finales fijos de la mayoría de las narraciones textuales o cinematográficas, los videojuegos tendrían como mínimo una base dicotómica (ganar o perder) que permitiría intuir la posibilidad de múltiples finales abiertos (exacerbados en los juegos de simulación). No obstante, para algunos autores, la idea del jugador como protagonista y la constatación del juego como secuencia de eventos producidos al manipular objetos (virtuales) con reglas formales constituye justamente, antes que una narración o un drama, el fundamento mismo de lo que se entiende por juego.

5 El signo de ruptura aquí, podría reflejarse en aquello que el investigador danés J. Juul objetaba en la figura del fracaso comercial de juegos como E.T. o Stars Wars. Estos productos eran ejemplos palpables de la diferencia estética entre videojuegos y la narrativa fílmica, al tiempo que anunciaban cómo los regímenes productivos de los mercados capitalistas afectaban al contenido como parte de la estratificación del agenciamiento en la industria cultural.

6 Para Scolari et al. (2013) las categorías que se erigen como fundamentos para el estudio de la relación entre tiempo y narración en la semiótica y en la narratología no parecen poder aplicarse totalmente a la textualidad interactiva. Para los autores, en los medios interactivos, el tiempo está suspendido, es cambiante, paradójico e indeterminado. 
Pero también, el acento puesto en la capacidad del juego para simular una serie de eventos antes que sólo representarlos, ha sido paralelo a la creciente importancia de la noción de interactividad. Esta confluencia de nociones ha hecho posible que muchos estudios con aspiraciones socio-semióticas se hayan ocupado de dar cuenta de las propiedades de la interacción definidas por la interfaz (cfr. Levis, 2013; Cabello, 2009; entre otros). Por ello, más allá de la dimensión representacional (de personajes, eventos, escenarios, tramas y tópicos), se ha hecho hincapié en las características de un jugador que actúa involucrando elementos audiovisuales-táctiles fundamentales. Quizás suene vago hablar de interactividad de los videojuegos, pero se nos perdonará la imprecisión de un término que intenta señalar que un juego supone siempre un tipo de acción del jugador. Con ello diversos investigadores españoles y latinoamericanos, mucho antes de los publicitados debates académicos angloparlantes, sentían la necesidad de afirmar una distancia, o, al menos, una diferencia ontológica entre la narración (escrita, oral, cinematográfica, etc.) y el videojuego. Como vimos esta diferencia, en algunos casos se señala diciendo que los juegos en tanto tales tienen reglas, eventos, resultados variables y una actividad configurativa del jugador. Estos elementos forman parte de la interactividad y de la simulación y sobre todo estructuran lo que se llama gameplay (como en diversos trabajos ha señalado el desarrollador e investigador uruguayo G. Frasca (2001)).

En paralelo a estas indagaciones, también comienzan a emerger conceptos, como el de inmersión, ajustados a una noción no siempre explicitada de corporalidad y de actividad comprometedora (Cabra, 2010). Pero también esta interacción lúdica, en el contexto que nos ocupa, por lo general, es puesta en segundo plano respecto de la interactividad propia de los nuevos medios digitales. Por lo tanto muchos de los estudios que han destacado esta dimensión se encuentran a mitad de camino entre las características lúdicas y las socio-técnicas, aunque por lo general las preocupaciones son de orden más fenomenológico que formalistas ${ }^{7}$ (Fernández, 2009; Molano y Martínez, 2006). Así, estas investigaciones se abocan al análisis exhaustivo de los componentes audiovisuales de la presentación como las cámaras virtuales y sus movimientos, las funciones cromáticas, la iluminación, etc. Sobre todo contemplando que las mismas construyen un mecanismo de interacción para guiar la atención del jugador y promover su actividad en el videojuego (Fernández Ruiz, 2011).

En parte, se podría decir que la interactividad aquí supuesta está estrechamente ligada a las reglas de juego encarnadas en diversos elementos, antes que abstraída en una serie de principios. Por ello, en confluencia con tendencias fenomenológicas, la interactividad ha sido trabajada en relación a la estructuración y construcción de los espacios, desde el punto de vista de la arquitectura de los mundos virtuales donde narración y simulación se convierten en el reverso de la inmersión (Pestano, 2012). Estos estudios dejan de sugerir que el videojuego puede ser comparado con un texto para señalar que el juego constituye siempre un espacio. Un mundo en el que los objetos aparecen como signos de determinadas funciones y acciones posibles con ellos y donde el ritmo y la tensión constituyen un elemento fundamental de la semiótica del videojuego (como anclajes para la generación de sentido) (Rossi, 2014). Respecto a la naturaleza de la interactividad, otros autores han especificado las influencias que tiene sobre el desarrollo de la narrativa en torno a su arborescencia o no linealidad, a su carácter diegético o extra-diegético, al conocimiento acabado del jugador sobre los personajes y elementos, etc. (Fernández, 2009; Fraile, 2009).

7 En el capítulo séptimo utilizaremos el término sincronización para señalar que las mecánicas soportadas por los estados de los juegos durante la gameplay conforman una alternativa para quebrar estas divisiones. 
No obstante, como queda sugerido en lo antedicho, narrativa e interactividad no se excluyen mutuamente, de hecho para algunos autores ya el mundo ficcional se vuelve necesario para que los jugadores puedan inferir las reglas de él. Aunque obviamente muchas veces esa ficción se asienta mejor en una tematización más que en una historia compleja o en un tratamiento psicológico de los personajes. Así también, en este amplio espectro, la narración y la interactividad encuentran un cariz particular de acuerdo a análisis de contenidos concretos que comprenden desde los elementos publicitarios implícitos hasta el belicismo, los deportes o las diversas temáticas de serious games (Barrientos-Gutiérrez, 2012; Tourn, 2013; Ortega-Ruiz y Velandia, 2011; Carmona, 2016; Golzio, 2011; Peláez, (s/f); Garduño, 2009). Debemos destacar aquí que el contenido rara vez es de manufactura local e independiente, así por lo general tienen predominancia casi exclusiva los análisis de contenidos generados por grandes estudios y publishers estadounidenses, europeos y japoneses. Aunque, a decir verdad, el análisis de juegos con un mayor compromiso social, como aquellos que intentan introducirse en los problemas medioambientales a través de las representaciones, despierta, ocasionalmente, el interés por los desarrollos del contexto regional que trabajamos (Lemos, 2013; Perales y Adam, 2012). Por otra parte, entretejidos con estos análisis de contenidos aparece la búsqueda constante de una distinción precisa de los videojuegos por géneros (deportivos, de acción, de disparos, etc.) o por temáticas (históricos, políticos, etc.) (Estallo, 1997; Polaino Carrasco, 2006).

Como se ve, muchos de estos análisis abordan directamente a los juegos desde sus capacidades de representación audiovisual y, por lo tanto, están conectados con problemas y dimensiones estéticas. En ese sentido, experiencias interesantes para nuestros objetivos son las investigaciones que constituyen las crónicas de invención de videojuegos, las indagaciones sobre metodologías de desarrollo (que suponen el modelo MDA (Mechanics, Dynamics, Aesthetics)) y los estudios sobre producciones audiovisuales (machinima) derivadas con intenciones estéticas a menudo enmarcadas en el Game art (Miguel y Martínez, 2011; Morales, 2010; Cedeño, 2010a-b; Feijó, 2010; Jacobo, 2012). En estos últimos estudios la pregunta por los desarrollos originales o intervenciones de jugadores, desarrolladores y artistas latinoamericanos y españoles es abordada de un modo más sistemático.

No obstante, frente a las perspectivas que señalan la íntima relación con los relatos, las posturas que indagan los elementos de la interactividad son menos numerosas. Menos aún se presentan aquellas que tratan de unir esos elementos interactivos con la noción de mecánicas y reglas de juego. Deuda que quizás puede ser atendida por futuros estudios mirando más de cerca lo que se ha llamado ludología en el ámbito anglosajón y en el norte de Europa, así como a la vasta bibliografía que han generado para tales fines. En alguna correlación con esta tarea, bajo la premisa de Huizinga que reza "todo juego significa algo", investigadores como el español O. Pérez (2011) han intentado trabajar al videojuego como medio de expresión, con tres dimensiones concatenadas: narrativas, discursivas y lúdicas ${ }^{8}$. Sus intentos han tenido resonancia en otros autores quienes, como sus pares angloparlantes, han sabido señalar que los videojuegos suponen reglas, interactividad, dinámicas e historias para analizar desarrollos en general o en particular (Swanson, 2016; Lozano, 2015; entre otros). Por último, estos estudios, sobre todo comprendiendo, como lo hacía Aaserth, al videojuego como texto ergódico señalan que aunque simulación

8 De hecho esta conciliación entre narración y reglas, interactividad y relato es explícitamente tematizada por los clásicos del campo. Sin necesidad de citar los mundos ficcionales del mimicry de Caillois, ya Aarseth, Murray, Turkle y Frasca suponen dicha mixtura. 
y narrativa puedan compartir elementos comunes (como personajes, ambientes y sucesos) sus estructuras semióticas difieren y en tanto tales necesitan de terminología específica. Pero es interesante notar la poca entidad que se ha dado a los análisis comparados como una vía para comprender a los videojuegos, quizás ello se deba a la falta de categorías y a las vastas dificultades para la construcción de grillas analíticas.

\section{Videojuegos, aprendizaje y educación}

En paralelo con estas aproximaciones, tanto en América Latina como en España, las ciencias de la educación configuran uno de los ámbitos más prolíferos de investigaciones abocadas a los videojuegos a partir, sobre todo, de su potencialidad para disparar el aprendizaje, el desarrollo y la enseñanza.

Una de las tonalidades recurrentes en este campo está aún relacionada con el discurso de los efectos y de los aprendizajes implícitos donde se asume que la tecnología impacta directamente sobre la conducta de los jóvenes y niños (entregados al consumo). En sus versiones más tradicionales, por lo general, la apelación a fundamentos neurobiológicos y psicológicos da lugar a la exploración de la co-variación de los tiempos de exposición delante de los videojuegos y diversos efectos no deseados ${ }^{9}$. En pleno diálogo con estos estudios, otros acercamientos psicológicos, han abonado a la hipótesis de aprendizajes implícitos como procesos en los que una información relevante es incorporada (de manera automática o no consciente) en el sujeto que realiza una tarea (Rehbein et al., 2008) ${ }^{10}$. Consecuentemente, la noción de impacto aparece de forma recurrente (Moncada y Chacón, 2012; Vara Robles et al. 2009; Tapia Meléndez, 2012; entre otros).

Uno se podría preguntar si el nacimiento de ese tipo de estudios no corre en paralelo a concepciones en tecnología educativa que moldearían ciertos desarrollos de videojuegos. Como rescatan Ito (2009) y Egenfeldt (2005), a mediados de la década de 1980 (y en Latinoamérica hacia principios de la de 1990), diversas tradiciones investigativas con fuertes sesgos instrumentalistas encuentran apoyo en la expansión de paquetes lúdico-educativos para los ordenadores hogareños (y en menor medida para las consolas). En particular, los autores señalan un nicho de mercado exclusivamente dedicado a la fusión entre entretenimiento y educación: el edutaiment (Mainer, 2006). En estos juegos, de una supuesta inspiración neo-conductista, se destacaban la insistencia en la repetición y el ejercicio por sobre los procesos de comprensión (lo que, como contrapartida, engendraba una experiencia de juego simplista e indicadores de reacción óculo-manual muy rápidamente citados por los psicólogos). Así, se generó una suerte de consenso sobre el valor de los videojuegos "educativos" para el refuerzo de las habilidades de alfabetización y matemáticas básicas, en un sistema que, quizás cumpliendo el mandato skinneriano,

9 Efectos que abarcan un amplio espectro y cuyos tópicos más recurrentes son el de la violencia y la agresividad (verbales y físicas), así como el de las conductas sociales negativas propiciadas por los contenidos (cfr. Martínez Lanz; Cano y Pérez; Vaca y Serrano; Huertas Rojas; Castro P. y Ramírez M; Canelón; Varela P.; Etxeberría, entre otros). En torno a la temática existe bibliografía que complejiza las preguntas (cfr. de Miguel; Estallo, 1997) y por supuesto abundan también en el mundo anglosajón (cfr. Kearney y Pivec). En Argentina, un exponente de esta línea es Sato. Pero también esos efectos se leen en otras direcciones como la obesidad, la autoestima, las iniciaciones sexuales precoces, el incremento del sedentarismo, los problemas de desatención, etc.

10 La manifestación empírica de dichos aprendizajes es la reacción ante patrones de señales que son ligados por los estudiosos con el desarrollo de reflejos, de la atención y de la agilidad mental. Se estudian así los tiempos de reacción y la inducción subliminal de respuestas en grupos experimentales de jugadores y no jugadores. 
podría prescindir del maestro. Avatares de una época con demasiadas esperanzas cifradas en las nuevas tecnologías cuyas consecuencias aún son legibles.

No obstante, en consonancia con las tendencias a nivel mundial, en Latinoamérica y España también pudo observarse, hacia mediados de la década de 1980, la aparición de investigaciones de fuerte raigambre cognitivista que, a lo largo del tiempo, se desarrollarían en posturas más flexiblemente constructivistas. Como tales, el centro de estas investigaciones (que en los casos más creativos llevaron al diseño de videojuegos exclusivamente para tales fines) lo constituiría la descripción y el análisis de las etapas de procesamiento de información (como anticipación perceptual, toma de decisiones, respuesta motora, etc.) en relación a un aprendizaje conceptualizado como elección correcta ${ }^{11}$ (Moranza et al., 1987). Paulatinamente, la psicología genética se asentaría como una de las líneas de investigación más fecunda en las que aparecerán múltiples estudios que se interrogarán sobre la visualización, la ubicación y las relaciones espaciales en relación al uso de videojuegos (Macías y Quintero, 2011; Rincón y Camargo, 2012; Gros, 2008; entre otros) $)^{12}$.

El cognitivismo ${ }^{13}$ llevó también a que los recurrentes resultados sobre la coordinación óculo-manual en el juego fueran sobrepujados hacia el estudio del aprendizaje de competencias específicas (Gros, 1998). En estudios derivados y sub-líneas de investigación dichas habilidades se muestran como el reverso de procesos de resolución de problemas, en algunos casos, en sentido de disciplinas particulares y, en otros, enfocando la ejecución de tareas concretas (como, por ejemplo, la correcta comprensión iconográfica). También fueron estudiadas detalladamente la implementación de estrategias, modelos mentales, planes de acción, búsqueda de elementos, seguimientos de la simulación, etc. (Mejía-Rodríguez, 2009; Goldin, 2014; Mainer, 2006). En conjunto con el tópico de las capacidades de la resolución de problemas, comenzará a indagarse el aprendizaje de competencias, así como la activación de esquemas y la memorización con anclaje en el videojuego. Por contrapartida, muchas de estas competencias van a estar también unidas a líneas de investigación subordinadas que hacen hincapié en contenidos curriculares específicos (que atraviesan todos los niveles educativos) y en experiencias didácticas vehiculizadas por videojuegos funcionales a un variado rango de disciplinas como biología, química, matemática, geometría, ingeniería, enfermería, historia, educación física, economía. etc. (Passos y Moita, 2011; Rincón y Camargo, 2012, Marchiori et al., 2012; Armenteros, 2006; Gálvez, 2006; entre otros).

El despliegue lógico de estas tendencias ha sido la construcción de instrumentaciones y propuestas curriculares que abonaron el terreno para una posible didáctica de los videojuegos (Montero, 2010; Group F9, 2000; Esnaola, 2012; Cabello, 2009; Moraldo, 2009; Calderón y López, 2010; Lacasa, 2011). Aunque muchas de ellas son herencias directas del aprender deleitando que ha moldeado la relación entre juego y

11 Esta dirección del análisis también sedimentará trabajos alternativos que se ocupen específicamente de sujetos a los cuales se les predican dificultades de aprendizaje.

12 Los resultados de muchas de estas investigaciones oscilarían entre no encontrar mejoras concretas (como el caso de la coordinación óculo-manual) y destacar algunos efectos alentadores como en el caso de las habilidades espaciales y la resolución de problemas. Como queda reflejado el enfoque de estos análisis excede a los contenidos de los videojuegos, no obstante es significativo que los estudios hayan pasado de la utilización de arcades de rápidos reflejos a los análisis que implementaban videojuegos con gameplay extendida como juegos de simulación, rol, estrategia en tiempo real y otros que destacaban por tener final abierto y, como lo describen diversos autores, fuerte anclaje en una cultura de pares.

13 En Argentina, la línea explicativa que reúne entrenamiento cognitivo y neurociencias ha sido desarrollada por el equipo de Goldin (2014), quienes han documentado modificaciones en funciones cognitivas especificas a través del videojuego (pero no se sabe si las mismas pueden ser trasladadas a otros contextos). Por ello, la validez ecológica de los resultados siempre es un coto infranqueable entre educación, aprendizaje y juego, pero, como veremos en el tercer capítulo, estos umbrales están relacionados con la estratificación de las prácticas lúdicas. 
educación en la Modernidad, no faltan aproximaciones críticas al currículum oculto de los videojuegos (Pereira y Gonçalves, 2011; Neves y Alves, 2013). Asimismo, en consonancia con el discurso sobre las competencias, es insoslayable la aparición de estudios dedicados a factores motivacionales en los videojuegos (Pérez Sánchez y Rumoroso, 2009).

Cuando, en la primera mitad de la década de 1990, los videojuegos comiencen a ser comprendidos como instrumentos culturales, la analogía con el lugar del lenguaje en los grupos vigotskianos (y sus versiones culturalistas) proveería un sustento teórico heurísticamente positivo para revitalizar los estudios sobre el entrelazamiento entre saberes, motivaciones y creación de significados a partir del juego. Al mismo tiempo, la alternativa de la teoría de la actividad socio-históricamente situada, encontraría un lugar paralelo a la fenomenología y a la teoría del actor en red como marco interpretativo de las tecnologías en la vida cotidiana (cfr. Kaptelinin). Por lo general, estas perspectivas que abren nuevas y fecundas líneas de estudio enfatizan los contextos del juego, sean estos sociales o áulicos, donde la artefactualidad es constitutiva de la condición humana. Una de las principales referentes y pioneras del campo ha sido la investigadora española Begoña Gros (2008), aunque también la recepción de otros autores angloparlantes (como P. Greenfield y M. Cole) ha sido de considerable importancia.

En estos grupos, la hipótesis será que los artefactos tecnológicos, entre los que no se deja de contar a los videojuegos, modifican nuestras formas de aprender y de producir conocimientos, al presentarse como dominios semióticos y simbólicos que enfatizan formas de representación visual o icónica. Para este constructivismo no sólo el conocimiento tiene origen social, sino que el propio proceso de aprendizaje permite potenciar habilidades comúnmente denominadas sociales relacionadas con la negociación, la toma de decisiones, la comunicación y la reflexión conjunta en el aula (Eguía et al., 2011). Todas estas posturas distinguen entre los videojuegos en el ámbito escolar y fuera del mismo.

Ligadas a la vertiente de psicología cultural, actualizando la noción de las dos modalidades de pensamiento (inspirada en J. Bruner, McEwan, P. Jackson, entre otros), el aprendizaje y la narración se vuelven a encontrar en el terreno de los videojuegos, a partir de estudios mixtos que unen análisis sociosemióticos ${ }^{14}$, aspectos afectivos y experiencias educativas tal como queda expresado en una de las investigaciones más sistemáticas y de referencia obligada como el de la autora argentina Graciela Esnaola (2006). Muchas de estas aproximaciones subrayan, como un valor fundamental, el aprender a contar historias a través de los videojuegos destacando, por supuesto, tanto la inmersión en la trama como los procesos identitarios facilitados por los mismos, así como el rol docente o del par más capaz (Esnaola y Levis, 2008; Mainer, 2006; Eguía, et al., 2011; Esnaola, 2012; Cabello [comp.], 2009; Landivar y Magallanes, 2006; Gómez-Martín, 2004; Garrido, 2013; entre otros). Por otra parte, entre estas aproximaciones no faltan perspectivas educativas que problematizan el vínculo entre videojuegos y sociedades de la información.

Si bien en algunos casos se ha comenzado a postular, incipientemente, la necesidad de ligar los procesos de invención y las modalidades de juego (Da Rocha, 2013), han sido las Ciencias de la Computación donde se ha indagado más sistemáticamente el desarrollo de competencias en el manejo de la información y el aprendizaje de la programación a través de los videojuegos (Naulin, 2009; Feijó, 2010). Ello va de la mano con la aparición de manuales de programación y diseño con públicos objetivos cada vez

14 Estos estudios no se limitan a los aportes de la Teoría de la actividad y entre sus análisis incorporan otras vertientes psicoanalíticas para caracterizar la afectividad inscripta en las vías narrativas. 
de menor franja etaria y con un viraje al interior de la teoría de la alfabetización digital (como es legible en la obra de J.P. Gee ${ }^{15}$ ). Colateralmente a estos estudios se ha indagado sobre algoritmos e inteligencias artificiales que condicionan la jugabilidad así como sobre entornos virtuales de aprendizaje mediante MMORPG ${ }^{16}$ y sobre el diseño de reglas interactivas en game engines (Trevisani y Cecchi, 2013; Moraldo, 2009; Merlino, 2013; Pérez Cota, 2009). Este variopinto grupo de investigaciones, que por lo general no provienen ya del campo de las humanidades y ciencias sociales, tiene una profunda consciencia de un fenómeno singular sobre el que podemos referir como epifanías de las técnicas o "technophanies"nombre con el cual el filósofo francés G. Simondon (2014) designaba la participación implícita en el sentido técnico que permite la transducción de valencias-símbolos en esquemas de funcionamiento.

\section{El videojuego como problema para las teorías sociales}

Además de algunos estudios híbridos con las tendencias anteriores, en el marco de las teorías sociales, se convirtieron en tópicos recurrentes las prácticas y frecuencias de juego ${ }^{17}$, las comunidades lúdicas en red, el uso del tiempo libre, las características de la industria, la evolución de las estrategias de mercado y las condiciones históricas de su aparición.

Como señalamos anteriormente, los primeros estudios sistemáticos sobre videojuegos se remontan a la década de 1990. En un primer momento, desde la comunicación social, se buscaron explicaciones para los salones de máquinas recreativas (arcades), las computadoras hogareñas y las consolas, comprendidos como fenómenos de masas particulares de lo que se comenzaba a pensar como sociedades de la información. Luego, ya en el siglo XXI, se abordaron tanto el auge como la decadencia de los espacios de juegos en red. En Argentina una de las impulsoras de esta rama ha sido la investigadora Roxana Cabello (pero también se encuentran estudios de Levis, 2003 o Huertas Rojas, 2005). Así, si los salones de juegos recreativos de las décadas pasadas, hasta donde sabemos, no conllevaron estudios específicos de las pautas de sociabilidad lúdica (aunque sí algunas reflexiones retroactivas, cfr. Feixa (en Gros,2008); Feixa, 2014) a comienzos de la década de 2000 , como parte de los estudios sobre juventudes, surgieron abordajes etnográficos de las experiencias culturales, prácticas comunicativas, juegos de lenguaje y pautas de sociabilidad en los cibercafés (sede de juegos en red).

Estas hipótesis llevaron a estudiar a los video-jugadores como grupo sociocultural, incluyendo sus expectativas y relaciones con las tecnologías, así como los espacios de socialización en tanto lugares de generación de sentido. Estos estudios preocupados por el consumo, las preferencias y los hábitos de los jugadores no han dejado de señalar, a través de encuestas y entrevistas en profundidad (a jugadores y dueños de locales), tanto el alto grado de violencia en los contenidos de los videojuegos, como el lugar

15 Los mentados trabajos de J. P. Gee sostienen que los videojuegos soportan formas sofisticadas de alfabetización situando el aprendizaje en medioambientes responsivos corporizados y desafiantes. Además el autor acentúa la naturaleza social y culturalmente situada del aprendizaje que tiene lugar durante el gaming.

16 Los videojuegos también han sido abordados desde los Estudios interculturales, señalando sentidos compartidos y diferenciados en intercambios culturales (cfr. Shuter), sobre todo haciendo hincapié en los contenidos y roles de los MMORPG. Se destacan aquí la figura del jugador prosumidor o generador de contenidos (cfr. Nyesito; Nakamura; y Ward) y las preguntas acerca de la estructura semiótica que soporta la producción de sentido (cfr. Bonenfant; y Genvo).

17 Algunos investigadores han diferenciado tipos de jugadores como subculturas (hardcore y casual según cfr. Juul). 
marginal de las mujeres ${ }^{18}$ en la cultura de los video-jugadores (Cabello, 2008, 2009, 2011; Turello, 2012; Alonqueo y Rehbein, 2008; Arango Forero et. al., 2010; San Román y López, 2006; Juárez et al., 2010). Alternativamente, estas aproximaciones ponían énfasis en los videojuegos como vía de masificación de la informática, prestando atención a los elementos de una interfaz exclusivamente construida para usuarios no especializados como indagó, por primera vez a nivel hispanoparlante, el investigador y referente argentino en la temática Diego Levis (2013 [1997]). Estas investigaciones no dejaron tampoco de estudiar los temas, géneros, tecnologías y tipologías más recurrentes de jugadores y de videojuegos, así como las tramas violentas en lo que clasificaban como nuevas formas de ocio virtual propias de una sociedad de consumo ( $y$ en algunos casos como formas de obtener beneficios económicos del uso del tiempo libre de los consumidores).

Asimismo, una rama transitada de estos estudios dio cuenta de la historia interna de los videojuegos como industria cultural. Esa historia recorre, sucesivamente, los desarrollos de la inteligencia artificial, las primeras pruebas experimentales surgidas en laboratorios cívico-militares, las batallas de las grandes empresas fabricantes y distribuidoras de consolas o la capacidad de procesamiento de la tecnología utilizada (Levis, 1997; Garfías, 2010; Bell y López, 2008; Nieto, 2006; Márquez, 2015). Cuando la historia de la industria se relaciona a los desarrollos locales, a veces se hace hincapié en el estrecho vínculo del nacimiento de la misma con las carreras relacionadas a las ciencias de la computación e informática (Esnaola et al. en Wolf, 2015). Pero también hay casos donde la historia del videojuego intenta ser interrogada desde la estratificación de las prácticas lúdicas que bregan por enfoques genealógicos que inquieran sobre la profunda relación de los videojuegos con los juguetes ópticos de mediados del siglo XIX y la conformación de un observador moderno en el capitalismo contemporáneo (Barinaga, 2012; Prados, 2001; Chausovsky y Rossi, 2015).

Como un vector desprendido de estos enfoques hay una marcada tendencia al análisis de los mercados, desde el punto de vista de la producción y el comercio de videojuegos. Así, hay estudios que identifican los focos de producción en España y Europa, como los tipos de desarrolladores y usuarios (García, 2012). En América Latina, conjuntamente al aumento de diferentes enfoques estadísticos y de encuestas, han aparecido estudios que destacan el crecimiento en la producción de videojuegos en paralelo a los avances tecnológicos, así como de la demanda de productos específicos como los casual games y las posibilidades de empleo en micro-unidades productivas como destaca el estudio pionero en la región de Bidart y Uman (2011). También se ha prestado atención al nacimiento de nuevos modelos de negocios como la distribución de juegos por internet. Al mismo tiempo, no es difícil encontrar estudios que focalicen en las dinámicas de desarrollo de los videojuegos en estudios de tamaño pequeño y mediano, haciendo hincapié en métodos productivos específicos y basando su estrategia analítica en lo que la industria denomina análisis post mortem (Miguel y Martínez, 2011; Morales Urrutia, 2010).

En un sentido similar, desde la sociología de la cultura, fueron estudiados los videojuegos como ejes de representaciones y significaciones sociales en la vida cotidiana infantil. Estos análisis integran al videojuego en una trama histórica de prácticas lúdicas (patios escolares, ámbitos familiares, juguetes, etc.) a partir de la reconstrucción de distintas generaciones (Duek, 2012; Quiroz y Tealdo, 1996). En ese

18 Una aproximación interesante a los problemas de género, han sido estudios que focalizan en la producción y juego con videojuegos. En particular, Juárez et al. (2010) han analizado las limitaciones de los estereotipos en el campo partiendo de evaluar la política de los artefactos o la "construcción sociocultural de la tecnología como adecuada para los hombres". 
marco otras investigaciones contemporáneas se han abocado al estudio de los videojuegos infantiles en redes sociales, haciendo particular énfasis en la estructuración de los contenidos, las formas de acceso, la interrelación entre fantasía y juego infantil (Tourn, 2013). Pero el estudio de las comunidades de juego digital, como vimos más arriba, no se restringe a los niños, sino que abarca también a adolescentes y adultos (Loayza, 2011; da Silva, 2009; Arango Forero et al., 2010; Bienvenido, 2012; Carmona, 2016).

Otra vertiente de análisis, que está directamente ligada a la sociología del trabajo, son las investigaciones sobre la producción y desarrollo de videojuegos en el contexto elegido. Un ejemplo es el estudio realizado por V. Xhardez (2013) sobre las prácticas laborales creativas en el capitalismo informacional. Si bien actualmente otras investigaciones en el campo también han reparado en entrevistas a los diseñadores de videojuegos locales, la autora enfoca al desarrollo de videojuegos en Argentina como labor informacionalsígnica y a la industria del videojuego como propia del sector de industrias creativas audiovisuales y de software. Puntualiza en los modelos de negocio, procesos de producción, estrategias de formación de recursos humanos, mecanismos de control y el management en dos estudios de desarrollo de videojuegos argentinos. Además analiza el trabajo creativo, las formas de valorización del capital y la realización personal como parte de las representaciones sociales de los trabajadores. Sin embargo, no se preocupa por las particularidades y los significados de lo que es inventado en la mentada industria creativa. En una línea similar investigaciones como las de Zangaro y Miguez (2013) o Zuckerfeld (2013) han esclarecido elementos fundamentales de la industria de videojuegos local y se han convertido en referencias obligadas para desentrañar la relación del desarrollo de juegos digitales con otros sectores en el capitalismo cognitivo.

En investigaciones emparentadas con estas direcciones de los análisis, C. Mendes (2006) estudia los videojuegos desde una perspectiva foucaultiana de la biopolítica. El investigador brasileño ha sido uno de los primeros en comprender a los juegos en el marco de la noción de gobierno como técnicas y procedimientos destinados a dirigir la conducta de los seres humanos. Con ello se ha abierto una línea de investigación sin par en el contexto angloparlante y muy fecunda en sus niveles heurísticos. Ella entra en consonancia con los estudios del investigador ecuatoriano I. Mendizábal (2004), quien ha intentado demostrar cómo los videojuegos se estructuran en tanto tecnologías de poder y de saber que ejercen un gobierno de los otros y del self. Mientras que, casi una década más tarde, S. Gómez (2014) postula la relación entre el capitalismo cognitivo, biopolítica y videojuegos.

En una línea homologable a estos abordajes podemos encontrar otras investigaciones con perspectivas similares, pero cuyo acento está puesto en las dimensiones cognitivas y afectivas construidas a partir de los videojuegos como tecnologías de las imágenes en el capitalismo global. Para ellos, los videojuegos son parte de un nuevo estatuto de la imagen que inaugura un régimen escópico, por lo que no es extraño que surjan otros estudios sociológicos que busquen comprender las categorías perceptivas e intelectivas presentes en los gamers (como suelen llamar a los jugadores). En particular, el investigador chileno Del Villar $(2003,2006)$ ha intentado abordar el problema de la brecha digital combinando la teoría de la estratificación social con la semiótica cognitivista. El autor enfatiza un presupuesto muy valioso: las categorías perceptivas e intelectivas inscriptas en el agenciamiento de juego contemporáneo son históricamente variables y el videojuego puede decirnos mucho al respecto. También ligado a las derivas del pensamiento sobre la filosofía de la técnica, otros estudios suelen reparar en la dimensión tecnológica de los juegos, haciendo hincapié en la recomposición de distinciones entre cuerpo y máquina, yo-otro, 
individuo-colectivo que son recompuestas a partir de la relación con la tecnología (Molano y Martínez, 2006; Mendizábal, 2004). Para ello, reparan alternativamente, como sostiene N. Cabra $(2010,2011)$ a partir de Deleuze y Guattari, en la interactividad como vía específica de los videojuegos para afectar las formas de percibir el espacio, el tiempo, la proximidad y la agencia.

En todas estas investigaciones aparece un tópico complejo de las modalidades de producción de subjetividades implicadas en los videojuegos, postulando así la necesidad de abordar en conjunto el continuum jugador-juego-cultura en el marco de lo que denominan sociedades de la información o capitalismo cognitivo.

\section{Conclusiones}

En primer lugar, hemos intentado trazar un mapa de los enfoques y tendencias de análisis más frecuentes sobre videojuegos. Esta aproximación no ha pretendido ser completa y detallada, sino que su máximo objetivo ha sido poner de relieve la importancia creciente del tópico para académicos de nuestra región idiomática, contextual y geográfica. En principio este trabajo puede servir de asidero a futuros investigadores que decidan estudiar algún aspecto particular de los aquí recorridos. Al mismo tiempo, aquellos académicos interesados en los videojuegos como objeto para investigaciones en Comunicación y en estudios culturales no pueden ignorar la diversidad de perspectivas que se han formulado sobre el epítome de los New Media. Investigaciones cuya diversidad abona la riqueza de la problemática y de la producción de conocimientos en regiones que, dadas las características de la producción de videojuegos, parecerían no tener peso en el ámbito internacional. La amplitud bibliográfica aquí presentada atestigua lo contrario. Los estudios sobre videojuegos en nuestra región no esperaron a las discusiones norteamericanas y del norte europeo para empezar, difundirse y dispersarse. A decir verdad, si tomamos el estudio de Moranza et al. (1987) como parámetro, podríamos decir que ya hace más de tres décadas que nuestro problema ha empezado a demandar constante indagación. De allí que, quizás parodiando las pretendidas fundaciones de campo ex nihilo, bien podríamos bautizar a este escrito "Games Studies, Year Thirty". Obviamente abonar a tal empresa fundacional no alimentaría más que la división y lo que necesita el campo es una reevaluación en términos de la totalidad. Lo cierto es que, lamentablemente, la dispersión ha abonado a un profundo desconocimiento de los análisis entre sí y, eventualmente, a la renuncia a explorar lo que se produce en contextos de producción de conocimiento más cercanos.

No obstante, en segundo lugar, el orden de los acápites y el punto donde abandonamos la reseña de la literatura existente no es azaroso y descubre quizás nuestros más profundos anhelos. Nuestra intención es que en estos últimos párrafos se adivine la dirección de posibles análisis y de estudios críticos. La idea de que los videojuegos, como agenciamiento de juego, tienen un rol fundamental en el capitalismo contemporáneo no es ajena o al menos subyace a la mayoría de las investigaciones presentadas en la sección anterior y se apoya en la concepción de una mutación en el capitalismo ${ }^{19}$. A ello corresponde que en las últimas investigaciones reseñadas se haga aparente un movimiento particular en la bibliografía del contexto idiomático y regional sobre videojuegos: a una apabullante cantidad de literatura sobre

\footnotetext{
${ }^{19}$ Como las que a menudo se postulan críticamente como capitalismo cognitivo o informacional, en contraposición a las
} posturas celebratorias de los estudiosos de la New Economy. 
jugadores, le han seguido estudios sobre trabajadores informacionales o cognitivos implicados en el desarrollo de videojuegos. El privilegio de estos análisis hasta hace un tiempo parecía corresponder solamente a los países en los que los estudios de desarrollo mainstream estaban guarecidos, quizás las condiciones de producción del mercado global capitalista han hecho variar esta tendencia. Como es sabido, luego de la crisis de 2008, las plataformas digitales de generación de data explotable, de producción y distribución digital de videojuegos bajo la comercialización outsourcing se han incrementado a un ritmo constante. Con ello, la región a la que nos abocamos además de ser blanco de jugadores (cuya génesis es paralela a la de los países centrales), comienza a convertirse en polo productivo. Así se han multiplicado los desarrollos de videojuegos propios de algunos nichos del mercado global (como el advergaming, los casual games o los serious games), que permiten escalas de producción relativamente pequeñas (en comparación con los grandes estudios y publishers estadounidenses, asiáticos y europeos). Pero al mismo tiempo esta posibilidad de producir juegos digitales desde nuestra región, sin dejar de postular las condiciones de producción del capitalismo contemporáneo (fragmentación, fragilidad, flexibilidad, precarización, etc.), también permite a los jugadores y trabajadores informacionales o cognitivos latinoamericanos y españoles encontrarse con vías de producción de ludotecas que excedan la mera reproducción de mecánicas, estados y reglas que han estriado el rostro de una de las de las industrias culturales más globales y penetrantes. De hecho a nadie debería sorprender que en esta nueva axiomática productiva globalizada se encierren vías de experimentación que puedan de contraponerse a los mandatos de una industria concentrada, oligopólica y verticalista (de allí el valor, también en nuestro contexto, que a menudo tienen los desarrollos indie y las jornadas de desarrollo y experimentación llamadas jams).

Así también quizás el lector al observar la diversidad de los enfoques que han tematizado a los videojuegos pueda postular una incompatibilidad teórica entre tantas y tan variadas tendencias. No obstante, el caso no es tal, pues si bien aún sigue siendo posible trabajar la diversidad temática aquí presentada desde disciplinas que no se esfuerzan demasiado por dialogar entre sí, ese tipo de decisiones puede obturar miradas más completas que permitirían aclarar el lugar de los videojuegos en las formaciones sociales contemporáneas. Puesto que, como en algún momento refirió R. Caillois sobre el juego, del videojuego puede predicarse ser un fenómeno total cuya riqueza sólo es perceptible para quien abandone los cercos disciplinarios y se apreste a hurgar en las múltiples corrientes que supieron descubrir en él aspectos decisivos.

Con todo y a pesar del amplio grado de dispersión, la centralidad de los videojuegos para el capitalismo informacional o cognitivo es un punto al que los analistas que hemos recorrido atribuyen valor, pero que no parecen explicitar salvo cuando el análisis tiene como acicate preguntas sociales críticas. Sin embargo, hemos de alentar un mayor interés por el conocimiento contextualizado y complejo. Así, por ejemplo, la actual división entre los investigadores que se dedican a comprender lo que denominan producción de sentido de los jugadores (a veces en términos hermenéuticos), aquellos que lo relacionan con algún aspecto educativo de las subjetividades disciplinarias y los analistas sociológicos y antropológicos de las condiciones de invención de videojuegos, no puede sostenerse sin soslayar cuestiones fundamentales como las que atañen a las vías de formación del cognitariado (cfr. Berardi, Dyer) que está detrás de aquellos jóvenes jugadores que hoy destacan como desarrolladores en un mercado global cada vez más demandante 
Por ello también es posible pensar, en tercer lugar, en próximos trabajos que permitan no sólo volver sobre muchos de los diferentes ejes planteados en los apartados anteriores sino también intentar conjugarlos yendo desde la complementariedad entre narración e interactividad hasta ciertas formas de comprender los procesos históricos de las prácticas lúdicas, pasando por el peso psicosocial de los videojuegos y su influencia en las vías del desarrollo. Para llevar adelante estudios de esa naturaleza, son necesarios conceptos que puedan hilvanar las relaciones entre poder, saber y subjetivación con las dinámicas del capitalismo contemporáneo. Hemos intentado en otros trabajos recorrer tales problemas concretos como el de agenciamiento videojuegos. Dicha noción, desprendida de la teoría social deleuzoguattariana, recupera el carácter social del juego, condensando los regímenes de signos y las máquinas socio-técnicas de nuestras sociedades contemporáneas como, en parte, lo han entrevisto la mayoría de los investigadores reseñados en el acápite anterior. Esta característica no sólo permite evaluar las transformaciones sufridas por las prácticas lúdicas, sino que además habilita explicaciones sobre cómo ellas se vuelven un factor fundamental en la formación de los desarrolladores o trabajadores cognitivos. No obstante, se trata sólo de un intento más entre varios que, teniendo en cuenta las advertencias de Caillois, han decidido que ya es hora de ambicionar un abordaje de la multiplicidad de los videojuegos en toda su complejidad. Con perspectivas de tal naturaleza los aspectos ontológicos, epistemológicos, estéticos, éticos, psicológicos y sociopolíticos del videojuego se encuentran nuevamente entrelazados impidiendo que la riqueza del problema se trueque por el afán de aumentar los anaqueles bibliográficos de estudios instrumentales y restringidos.

\section{Bibliografía}

Alonqueo, P. y Rehbein, L. (2008). "Usuarios habituales de videojuegos". Última Década, n. 29, diciembre, pp. 11-27.

Arango Forero, G.; Bingué Sala, X.y Sádaba, C. (2010). "La generación interactiva en Colombia: adolescentes frente a la Internet, el celular y los videojuegos". Revista Anagramas, vol. 9, n. ${ }^{\circ}$ 17, julio-diciembre, pp. 45-56.

Armenteros, M. (2006). "Aprendizaje de las reglas del Fútbol a través del videojuego". Icono14, vol. 4, n 2, p. 9 y ss.

Balaguer, R. (2007). "Antiguas y actuales narrativas. La ficción en la nueva narrativa de los videojuegos". Psikeba: Revista de Psicoanálisis y Estudios Culturales, nº 5.

Barinaga, B. (2012). "Del Juego Antiguo al Juego de Computadora" Revista Icono 14, España, vol. 4, no 2, p. $139-156$.

Barrientos-Gutiérrez, T. et al. (2012). "Se busca mercado adolescente: internet y videojuegos, las nuevas estrategias de la industria tabacalera". Revista de Salud Pública de México, vol.54, n 3, pp. 303-314.

Bell, S. y López, C. (2008) "Breve historia de los videojuegos". Athenea Digital, nº 14, pp. 159-179.

Bidart, S. y Uman, V. (2011). "La industria de desarrollo de videojuegos: Argentina" en: Bertín, C. et al., Guerra y paz en el mundo virtual. Datos y debates sobre videojuegos. Chile, Centro de estudios Universitarios. 
Bienvenido, H. (2012). "Análisis crítico de Diablo III: el mito del juego irreal". Teknokultura, vol. 9, n. ${ }^{\circ} 2$, pp. 149-156.

Blanco, M. y Jáuregui, K. (2010). Videojuegos: las apariencias ¿engañan? Prácticas, relaciones e interacciones de los jóvenes usuarios de juegos en red. Buenos Aires: Observatorio de Jóvenes, Comunicación y Medios. Universidad de la Plata.

Cabello, R. (2008). Las redes del juego. Buenos Aires: Prometo Libros.

- (2009) Ciberjuegos. Escritos sobre usos y representaciones de los juegos en red. Buenos Aires: Imago Mundi y Universidad Nacional de Genera Sarmiento.

Cabra, N. (2010). "Videojuegos: máquinas del tiempo y mutaciones de la subjetividad" Signo y Pensamiento, vol. 29, $\mathrm{n}^{\circ}$ 57, pp. 162-177.

(2011). "Entre el fantasma, el avatar y otras mutaciones de la imagen". Revista Nómadas, Universidad Central, Colombia, n. ${ }^{\circ}$ 35, octubre, pp. 81-97.

Calderón, A. y López A., A. (2010). "Usos del videojuego "Rise of the Nations" en el proceso de enseñanza-aprendizaje en el programa de Ingeniería Industrial de la Universidad Icesi" Revista en Ciencias Sociales CS, Cali, $\mathrm{n}^{\circ} 6$, julio, pp. 101-128.

Carmona, M. (2016). "Las redes sociales y los videojuegos como mecanismos de captación del Daesh". Revista de Pensamiento Estratégico y Seguridad, vol. 1, n. ${ }^{\circ}$ 2, pp. 65-76.

Cedeño, R. (2010). "Machinima un medio híbrido: películas animadas usando videojuegos." Revista Clave, Bogotá, $n^{\circ} 3$, pp. 37-51.

(2010b) "Medios. Hazlo tú mismo: Machinimas y otras bestias híbridas." Foro DesConCentrar el Diseño, pp. 2-5, Bogotá.

Chausovsky, A. y Rossi, L. (2015). "De los juguetes ópticos a los videojuegos: discusiones sobre la materialidad de las imágenes". Revista Lúdicamente, Vol. 4, n. ${ }^{\circ}$, pp. 3-18.

Da Rocha, D. et. al. (2013). "Criando Videogame na Escola". En: Ferreira, C. y Tavares, R. (Eds.) Videojogos $20125^{a}$ Conferência Anual Em Ciência E Arte Dos Videojogos. Faculdade de Ciências Humanas, Universidade Católica Portuguesa.

Da Silva, R. (2009). "Entretenimento no Second Life: como as redes criam tramas cada vez mais complexas" Intercom. Sociedade Brasileira de Estudos Interdisciplinares da Comunicação. XIV Congresso de Ciências da Comunicação na Região Sudeste, Rio de Janeiro, 7 a 9 de mayo de 2009.

David, J. y Blasco, M. (2006). Abriendo el juego. Buenos Aires: Lumen.

Del Villar, R. (2003). "Análisis semiótico comparativo videoanimación americana/japonesa". Comunicación y Medios, vol. 13, n. ${ }^{\circ} 14$, pp. 1-10.

(2006) "Brecha digital, categorías perceptivas y cognitivas: el caso de los videojuegos". Revista del instituto de la comunicación e imagen. Universidad de Chile. nº 17, pp.5768.

Duek, C. (2012). El juego y los medios: Autitos, muñecas, televisión y consolas. Prometeo Libros.

Egenfeldt, S. (2005). Beyond edutaiment. Tesis doctoral IT-University of Copenhagen.

Egenfeldt, S. y Tosca, S. (2008). Understanding video games. Nueva York: Routledge.

Eguía, J. L. et al. (2011) "Videojuegos como un entorno de aprendizaje: el caso de" Monturiol el joc"". Icono 14, vol. 2, nº 9., pp. 249-261. 
Eskelinen, M. (2012). Cybertext poetics: the critical landscape of new media literary theory. Bloomsbury Publishing USA.

Esnaola, G. (2006) Claves culturales en la organización de conocimiento ¿Qué enseñan los videojuegos? Buenos Aires: Alfagrama.

Esnaola, G. y Levis, D. (2008). "La narrativa en los videojuegos: un espacio cultural de aprendizaje socioemocional" Revista Electrónica Teoría de la Educación. vol. 9. nº 3.Noviembre, pp. 48-68.

Esnaola, G. et al. (2015). "Argentina" en: Wolf (2015) Video games around the world. Massachusetts : MIT Press.

Esnaola, G. et. al. (2012). "videojuegos en aula: una herramienta de evaluación educativa". I Jornadas Nacionales de TIC e Innovación en el Aula y III Jornadas de Experiencia en EaD de la UNLP.

Estallo, J. A. (1994). "Videojuegos, personalidad y conducta". Revista Psicothema, vol. 6 n. ${ }^{\circ}$ 2, pp. 181190.

Estallo, J. A. (1997). Psicopatología y Videojuegos. Barcelona: Institut Psiquiàtric.

Feijó, B. (2010) Introdução à ciência da computação com jogos: aprendendo a programar com entretenimento. Rio de Janeiro: Elsevier.

Fernández Ruiz, M. (2011) "Elementos visuales expresivos en la interactividad del videojuego" Revista Razón y Palabra. N. ${ }^{\circ} 75$. en: http://www.redalyc.org/html/1995/199518706063/

Fernández, J. (2009). "Interacciones hipermedia y videojuegos." Revista Icono14, vol. 7, n 1, pp. 12-27.

Fraile, A. (2009). "Sobre el lenguaje de la virtualidad: los géneros de videojuegos como géneros de mundos virtuales". Eikasia: revista de filosofía, n²4, p. 15-28.

Frasca, G. (2001). Videogames of the oppressed. Tesis Maestría. Georgia Institute of Technology.

Gálvez, M.C. et al. (2006). "Aplicaciones de los videojuegos de contenido histórico en el aula." Icono14, 2006, vol. 4, n 1, p. 12.

García, J. (2012). "El mercado del videojuego: Unas cifras". Revista ICONO14. vol. 4, n 1, p. 36-47.

Garduño, A. E. (2009). "La Práctica del deporte a través del WII Nintendo". Razón y Palabra, vol. 14, n. ${ }^{\circ}$ 69. en: http://www.redalyc.org/html/1995/199520330060/

Garfías Frías, J. Á. (2010). "La industria del videojuego a través de las consolas". Revista mexicana de ciencias políticas y sociales, vol. 52, n. ${ }^{\circ} 209$, pp. 161-179.

Garrido Miranda, J. (2013). "Videojuegos de estrategia: algunos principios para la enseñanza". Revista Electrónica de Investigación Educativa, vol. 15, n 1., pp. 62-74.

Goldin, A. et al. (2014). "Far transfer to language and math of a short software-based gaming intervention" Proceedings of the National Academy of Sciences, vol. 111, n. ${ }^{\circ} 17$, pp. 6443-6448.

Golzio, D. y Mendes, O. (2011) "Jogos de guerra e estereótipo do terrorista no videojogo America's Army: territorialização, guerra e alteridade islâmica." Culturas Midiáticas, 2011, vol. 1, no 1, PP. 1-10.

Gómez, S. (2014) "Ludocapitalismo: videojuegos y la creación de subjetividades en la economía digital" Actas de la primera Jornada transdisciplinar de estudios en gubernamentalidad. 1 al 4 de septiembre de 2014.

Gómez, M. et al. (2004). "Aprendizaje Basado En Juegos". Revista Ícono 14. Año 2. Vol. 2. pp. 1-13.

Gros, B. (1998) (Coord.) Jugando con Videojuegos: educación y entrenamiento. Bilbao: Desclée de Brpuwer.

Gros, B. (2008) Videojuegos y aprendizaje. España: Grao. 
Group F9 (2000) "Ocho propuestas didácticas". Cuadernos de pedagogía. №. 291,Mayo 2000.

Huertas Rojas, F. (2005) "La violencia virtual: una experiencia de los jóvenes en las videosalas." Estudios Sociales, vol. 13, nº. 26, julio-diciembre, pp. 172-206.

Ito, M. (2009). Engineering Play. Cambridge: MIT Press.

Jacobo, M. (2012). "Videojuegos y arte. Primeras manifestaciones de Game Art en Argentina." Cuaderno 41. pp 99-108 .

Juárez, A. et al. (2010). "Performatividad Tecnológica de Género: Explorando la Brecha Digital en el mundo del Videojuego". Quaderns de psicologia. International journal of psychology, vol. 12, $\mathrm{n}^{\circ}$ 2, pp. 209-226.

Juul, J. (2005) Half-real: Video games between real rules and fictional worlds. MIT press.

Lacasa, P. (2011). Los videojuegos. Ediciones Morata.

Landivar, T. y Magallanes, S. (2006) "Alumnos, docentes y videojuegos". I Congreso de Tecnología en Educación y Educación en Tecnología. Agosto de 2006.

Lemos, L. (2013). "Narrativas de buscas na promoção de saúde em games". En líneahttp://www.sbgames.org/sbgames2013/proceedings/cultura/Culture-2_full.pdf Consultado octubre de 2013.

Levis, D. (2003). "Videojuegos: cambios y permanencias." Comunicación y Pedagogía, vol. 184, pp. 65-69.

Levis, D. (2013 [1997]). Videojuegos, un fenómeno de masas. Buenos Aires: Sivel, Palabras escritas.

Loayza, J. (2011). "Sensibilidades y videojuegos en línea: un análisis de la frontera entre lo real y lo virtual en América Latina". Revista Austral de Ciencias Sociales n. ${ }^{\circ} 20$, pp. 19-40.

Lozano, A. (2015). "Jugar, explorar, sufrir construcción del horror en la estética de los videojuegos". Disponible en: institucional.us.es/fedro/uploads/pdf/n15/Lozano.pdf

Macías, G y Quintero, R. (2011). "Los videojuegos como una alternativa para el estudio y desarrollo de la orientación espacial" http://funes.uniandes.edu.co/1825/1/396 Macias2011Losvideojuegos SEIEM13.pdf

Mainer, B. (2006). "El videojuego como material educativo: La Odisea". Icono 14., vol. 1, n. ${ }^{\circ}$ 4, pp. 48-76.

Marchiori, E. et al. (2012). "Instrucción en maniobras de soporte vital básico mediante videojuegos a escolares." Revista de la Sociedad Española de Medicina de Urgencias y Emergencias, vol. 24, n. ${ }^{\circ}$ 6, pp. 433-437.

Márquez, I. (2015). Una genealogía de la pantalla: del cine al teléfono móvil. Barcelona: Anagrama.

Mejía, C. et al. (2009). "Mentes, videojuegos y sociedad. Algunos puntos cruciales para el debate." Revista Cientifica Guillermo de Ockham, vol. 7, nº. 1, pp. 19-30.

Mejía, C. y Rodríguez, M. (comp.) (2009). I/O Videojuegos, Computadoras y seres humanos. Cali, Editorial Bonaventuriana.

Mendes, C. L. (2006). Jogos Eletrônicos: Diversão, Poder E Subjetivação. São Paulo: Papirus Editora.

Mendizábal, I. R. (2004). Máquinas de pensar: videojuegos, representaciones y simulaciones de poder. Quito: Universidad Andina Simón Bolívar, Ediciones Aiya-Yala.

Merlino, H. et al. (2013) "Sistemas inteligentes en arquitecturas de motores para videojuegos". XV Workshop de investigadores en Ciencias de la Computación. Paraná, Entre Ríos. Pág. 990-993. 
Miguel, J. C. y Martínez, J. C. (2011). "'Buccaneers of Symeria": idea y concepto. Crónica de desarrollo de un videojuego." Creatividad y sociedad: revista de la Asociación para la Creatividad, n. ${ }^{\circ} 16$, pp. 425.

Molano, M. y Martínez Loné, P. (2006). "La dimensión simbólica del jugador de videojuegos". Icono14, 2006, vol. 4, no 2, pp. 1.

Moncada, J. y Chacón, Y. (2012). "El efecto de los videojuegos en variables sociales, psicológicas y fisiológicas en niños y adolescentes" en: Retos. Nuevas tendencias en Educación Física, Deporte y Recreación, no 21, pp. 43-49.

Montero, E (Coord.) (2010). Aprendiendo con videojuegos. Jugar es pensar dos veces. Madrid: Narcea.

Moraldo, H. (2009). "Desafíos y tendencias en el diseño de videojuegos" .Comunicación, № 7, Vol.1, año 2009, PP. 6-15.

Morales, G. et al. (2010). "Procesos de desarrollo para videojuegos". CULCYT// Año 7, n 36/37, enero abril.

Moranza, L. et. al. (1987). "Utilización de un video-juego computarizado diseñado para la evaluación conductual de niños con dificultades para aprender". Revista Mexicana de análisis de la Conducta. vol. 13. n. ${ }^{\circ} 1$ y 2 , pp. $75-85$.

Naulin, F. y Seguel, J. (2009). Los Videojuegos y el desarrollo de competencias de información, Departamento de Gestión de Información de la Universidad Tecnológica Metropolitana. Disponible en: http://core.ac.uk/download/pdf/11885978.pdf

Navarrete, J. L., et al. (2014). "Una aproximación a los paradigmas de la Teoría del Videojuego". ZER. Revista de Estudios de Comunicación, vol. 19, n. ${ }^{\circ} 37$, pp. 107-121.

Neves, I. y Alves L. (2013). "Jogos Digitais e a Constituição de Saberes." En: Ferreira, C. y Tavares, R. (Eds.) Videojogos 20125 a Conferência Anual Em Ciência E Arte Dos Videojogos. Faculdade de Ciências Humanas, Universidade Católica Portuguesa.

Nieto, D. (2006). "Análisis del contexto histórico y tecnológico del origen de los videojuegos". Icono14, 2006, vol. 4, n², pp. 68-86.

Núñez, J. R. (2007). "El origen de las aventuras gráficas: La ficción interactiva" .CDC Cuadernos de Comunicación, vol. 1, pp. 154-163.

Ortega-Ruiz, C. A. y Velandia-Morales, A. (2011). "Influencia del advergaming y el advertising en la recordación y reconocimiento de una marca". Revista Latinoamericana de Psicología, vol. 43, nº 3, pp. 511-520.

Passos, É. y Moita, F. (2011). "A tecnologia e o ensino de química: jogos digitais como interface metodológica" En: Sousa, R. et al. (Eds.) Tecnologias Digitais na Educação. Campina Grande: Editora da Universidade Estadual da Paraíba.

Peinado, F., y Santorum, M. (2006). "De cómo la realidad puede tomar parte en juegos emergentes." Revista ICONO14. N. ${ }^{\circ}$ 8, pp. 53-67.

(2004) "Juego Emergente:¿nuevas formas de contar historias en videojuegos?". Icono14, 2004, vol. 2, n. ${ }^{\circ} 4$, pp. 47-57.

Peláez, B. (2009). "Fútbol y videojuegos: reinventando el juego". Revista Razón y Palabra. Disponible en línea en: http://www.redalyc.org/html/1995/199520330059/ 
Perales, V. y Adam, F. (2012). "El contrato natural. Aproximaciones desde el videojuego." Revista ICONO14. vol. 4, n², pp. 36-52.

Pereira, A. y Gonçalves, F. (2011) "Os jogos como contextos curriculares: um estudo das construções de gênero no "The SIMS"'". En: de Sousa, Robson et al. (Eds.) Tecnologias Digitais na Educação. Campina Grande: Editora da Universidade Estadual da Paraíba.

Pérez Cota, M. et al. (2009). "Estudio de mundos virtuales para mejorar el aprendizaje". XI Workshop de Investigadores en Ciencias de la Computación. Mayo 2009. pp. 705-709. Disponible: http://sedici.unlp.edu.ar/handle/10915/19870

Pérez Sánchez, R. y Rumoroso, A. (2009). "El Uso de Tecnologías de la Información y la Comunicación y la Evaluación de Sí Mismo en Adolescentes Costarricenses". Interamerican Journal of Psychology, vol. 43, núm. 3, 2009, pp. 610-617.

Pérez, M. M. (2010). "Narrativa en las aventuras gráficas." Frame: revista de cine de la Biblioteca de la Facultad de Comunicación, nº 6, pp. 243-264.

Pérez, Ó. (2011). El discurso videolúdico. Barcelona: Laertes.

Pestano R., J. et al. (2012) "Elementos diferenciales en la forma audiovisual de los videojuegos. Vinculación, presencia e inmersión." Revista Mediterránea de Comunicación Social, año 3, n 1, pp. 1-13.

Planells, A J. (2013). "La emergencia de los Game Studies como disciplina propia" Historia y Comunicación Social, 2013, vol. 18, pp. 519-528.

Polaino Carrasco, R. (2006). "Propuesta de tipología básica de los videojuegos de PC y consola". Icono14, vol. 4, n० 1 , pp. 1-15.

Ponce, Á. y García, F. (2012). "Videojuegos trasladados al cine: análisis y caracterización de la narrativa audiovisual en ambos medios." Comunicación: revista Internacional de Comunicación Audiovisual, Publicidad y Estudios Culturales, vol. 10, pp. 63-77.

Prados, M. (2001). "Los videojuegos a la luz de la historia del juego y del juguete". Signo y pensamiento, vol. 20, no 39, p. 54-64.

Quiroz, M. y Tealdo, A. (1996). "Los videojuegos y los niños peruanos: tiempo libre y procesos de socialización". Estudios sobre las Culturas Contemporáneas, vol. II, nº. 4, diciembre, pp. 95-123.

Rehbein, L. y Alonqueo, P. (2008). "Aprendizaje implícito en usuarios intensivos de videojuegos." Paidéia, vol. $18, \mathrm{n}^{\circ} .39,2008, \mathrm{pp} .165-174$.

Rincón Acevedo, J. y Camargo, L. (2012). "El Tetris como mediador visual para el reconocimiento de movimientos rígidos en el plano (rotación y traslación)". Revista Tecné, Episteme y Didaxis n. ${ }^{\circ}$ 32, julio, pp. 23-36.

Rossi, L. S. R. (2014). "Las ciudades y los medios acuáticos en los videojuegos". Letra. Imagen. Sonido. Ciudad Mediatizada, n. ${ }^{\circ} 10,29-43$.

San Román, J. y López, M. (2006). "Uso de videojuegos en niños de 7 a 12 años: una aproximación mediante encuesta". Icono14, 2006, vol. 4, no 1, pp. 11.

Scolari, C. ed. (2013). Homo videoludens 2.0. De Pacman a la gamification . Collecció Transmedia XXI. Barcelona: Universitat de Barcelona.

Simondon, G. (2014) Sur la technique. París: PUF. 
Swanson, R. (2016). "Narración e interactividad en los videojuegos." Estudios Lambda. Vol. 1, n. 1, pp. 63-83.

Tapia M., L. (2012). "Estimulación y relax mental a través del uso de videopasatiempos de última generación" Revista ICONO14. vol. 4, n², p. 99-115.

Thabet, T. (2015). Video Game Narrative and Criticism. Playing the Story. Springer.

Torres, C. R. et al. (2015). "Videojuegos como simulaciones inmersivas. El caso "Atrapados"'" Narrativa transmedia. PAPELES, vol. 6, n. ${ }^{\circ}$ 12-13, pp. 47-62.

Tourn, G. (2013). "Jugar en tiempos de Facebook". Lúdicamente, vol. 2, n. 3.

Trevisani, D. y Cecchi L. (2013). "Estrategias de formación de grupo en videojuegos RTS con ambientes dinámicos". XV Workshop de investigadores en Ciencias de la Computación. pp. 841-845 Paraná, Entre Ríos.

Turello, M. (2012). "Del ciber a la casa: apropiaciones de juegos en red y relaciones entre pares". III Reunión Nacional de Investigadoras/es en Juventudes Argentina. Red de Investigadores/as en Juventudes de Argentina. Viedma.

Vara R., E. et al. (2009). "Impacto del abuso de pantallas sobre el desarrollo mental." Pediatría Atención Primaria, vol. 11, n 43, pp. 413-423.

Xhardez V. (2013). El trabajo en juego. Trabajo "creativo" y organización productiva en la Industria Cultural de Videojuegos: implicaciones socio-económicas. Tesis Doctoral en Ciencias Sociales. Universidad de Buenos Aires.

Zangaro, M. y Míguez, P. (2013) "El trabajo inmaterial -cognitivo y sus consecuencias para los trabajadores: el caso paradigmático del desarrollo de videojuegos". VII Congreso Latinoamericano de Estudios del Trabajo EI Trabajo en el Siglo XXI. Cambios, impactos y perspectivas.

Zukerfeld, M. (2013) Obreros de los bits. Conocimiento, trabajo y tecnologías digitales. Bernal, Universidad Nacional de Quilmes Editorial. 